\title{
INDUSTRIAL DESIGN COURSE IN A LOW-DENSITY REGION
}

\author{
Afonso BORGES ${ }^{1,2}$ and José VICENTE ${ }^{3,4}$ \\ ${ }^{1} \mathrm{ID}+$, Universidade de Aveiro, Portugal \\ ${ }^{2}$ Faculdade de Artes e Letras, LABCOM, Universidade da Beira Interior, Portugal \\ ${ }^{3}$ IADE, UNIDCOM, Universidade Europeia, Portugal \\ ${ }^{4}$ Faculdade de Arquitetura, CIAUD, Universidade de Lisboa, Portugal
}

\begin{abstract}
A look at the international reference courses in the field of industrial design seems to reveal a significant concentration in developed regions with a high industrial and solid creative development, most usually in large cities, invigorated by a thriving business and supported in a dynamic cultural scene. This starting point implies the question of whether this context is mandatory or decisive to the existence of healthy higher education in industrial design.

This article seeks to present, explain and analyse an industrial design university programme in a peripheral, non-industrial region, with a fragile economy and an aged population, trying to debate scientific, pedagogical and university extension features, namely community relations, course strategy, so this programme can provide quality learning for future industrial designers in the global context.

This paper aims to question, discuss and help answer these doubts, using as a case study the 1st and 2nd cycle courses in industrial design, promoted at the University of Beira Interior, located in Covilhã, in the inland of Portugal. The characteristics of these courses will be presented and discussed, seeking to demonstrate how a clear definition of a strategy has become essential for the success of design education in peripheral regions.
\end{abstract}

Keywords: Design education, industrial design, industrial development, low-density regions

\section{INTRODUCTION}

This paper seeks to analyse the nature of an industrial design course of a public university in a peripheral and low-industrialised area. With an approach based on memory and evolutive design, not ignoring local heritage, but focused on an internationalist vision, this article explains how the work process contributes to the consolidation of this strategy, also allowing to document the strategy and the thinking that supported a recent restructuring process. More than the specific course, this case study seems to reflect and allow discussion on many similar situations.

\section{INDUSTRIAL DESIGN AND CONTEXT}

\subsection{Industrial Framework}

Analysing the landscape of Portuguese design, of its brands, manufacturers and designers, it quickly emerges that the ecosystem of industrial and product design is concentrated in large cities, in areas with strong development and consistent cultural dynamics. In recent data, published in 2016, manufacturing represented $10 \%$ of Portuguese companies, accounting for $25 \%$ of turnover and employing 660,000 people, of which $51 \%$ were in the north of the country [1], with greater expression on the coast, concentrated in an area below one-sixth of the total territory. In a country with weak industrialisation and a deficient trade balance [2], the proximity between the designers and industry is also fragile and deficient, with most of the largest design studios, with the greater recognition and international awards, placed close to the large urban centres of Porto and Lisbon. 


\subsection{Design Education}

The proximity to industry and decision-making centres; the concentration of $60 \%$ of the Portuguese population (of which 75\% in the metropolitan areas of Lisbon and Porto) and $83 \%$ of the wealth produced on the coast; the concentration of higher education students in coastal establishments (89\%), particularly in Lisbon and Porto (54\%), by far the highest in Europe [3]; the tradition associated with the appearance of the first design courses in Fine Arts schools, also in Lisbon and Porto; have resulted in the concentration of design education, particularly industrial and product design, in more developed regions. Considering a total of 51 first cycle degree design courses, 34 belong to coast institutions, of which 16 are in the two largest cities. The difference in the number of students is even more pronounced, with $77 \%$ of annual student admission for design courses concentrated, and only $23 \%$ enrolled in schools that can be considered inland or peripheral [4].

A clear strategy for national design education is not known, particularly for the definition of the nature of each course, which is defined by the most diverse factors; from the relationship with local industry; to their origin, either the tradition of artistic design training in Fine Arts schools, or engineering schools, as is the case of University of Beira Interior (UBI) industrial design degree; or simply reflecting the perspective of its creators. Although, more or less conscious, there seems to be a specific identity in each school or course, and this apparent lack of coordination seems to have provided freedom in the definition of the programmes by the schools, and a wider diversity of supply.

UBI, the public university that hosts the course, is in the upcountry, in highlands of woollen tradition, today little industrialised, and, if we don't consider the temporary student population, of aging population. On the other hand, despite the overwhelming concentration of design education in large centres, we can find in small cities or peripheral regions, through history and today, throughout Europe and the world, a few examples of good or even reference schools. The most immediate examples of the Bauhaus, founded in Weimar, transferred to Dessau, and of the Design School of Ulm. But even in the current context, a few recognised schools, as the Scandinavian UMEA, Kolding or LUT, operate in somehow peripheral areas, although eventually not economically depressed regions. The UBI industrial design course has no intention of copying any of these specific models but, in the recent restructuring of its course, occurred in 2015, has taken these cases in consideration.

\subsection{Change}

In recent decades, there seem to have taken place two very significant changes in the landscape of national and international design, with impact in the decentralisation of design.

The first change is related to the popularisation of the term design, its democratic adoption and, to some extent, to have become fashionable, even vulgarised [5], giving rise to an exponential growth in the number of courses and students. Portugal training grew from three higher education institutions with four first cycle design courses in 1989, to 29 schools, public and private, with 51 courses, in the interval of thirty years [4], studies plans often generated within technical schools, sometimes transforming professional character courses into design degrees.

The second change, non-country-specific, consists of miniaturisation, digital, or more recently, and even with non-anticipatory effects, 3D print technologies and their alleged potential of creating a Third Industrial Revolution [6]. Associated to democratisation and with the success of online sales, which are today directed to global niches, transforming market into markets [7], the change seems to expand, in a digital era version. In Konstantin Grcic's point of view [8], the notion of industry as an abstract entity simply ceased to exist.

Not ignoring factors such as proximity and personal trust, often associated with the definition of the brief [9], these two changes, particularly the second one, allowed decentralisation in several levels. Allowed decentralisation of production, which became viable to a lesser extent, in small customised series, softening the dependence on centralised industry, and allowing the appearance of smaller productive structures, sometimes only dependent on assembly. Allowed decentralisation of the design project, becoming possible to be developed in any place, by the internet, in a collaborative way and smaller offices. And also, allowed decentralisation of sales, which became possible with any simple computer, from anywhere and to any destination.

These changes can reduce the feeling of periphery, bringing the whole world closer, eventually reducing the notion of distance to the centres of decision that is often associated with courses in nonindustrial zones. 


\subsection{UBI Approach}

A realistic approach, based on a work process grounded in the design studios work routine observation, is one of the fundamental approaches intended in the industrial design studies cycle at UBI, and part of the nature of its degrees. The realistic approach seeks to respond to student's anguish about the future by focusing on processes that are like those found in design project work. The approach is accentuated by developing products of daily use, eventually also equipment with which we do not live every day, but always typologies that are real, that exist, as explored by Konstantin Grcic in Design-real exhibition. According to Bazon Brock [10], these common objects are the ones that will allow the analysis and portray of our era, in the same way that part of the understanding of our human nature was allowed by Pompey, portrayed and preserved by the ashes of Vesuvius. As the artefacts made by man are all that exists beyond us and nature, their existence and the relationship with them is, to a large extent, what makes us human [11]. With this realism and approach to industry, we seek to avoid what Sam Hecht [12] considers to be a growing gap between design teaching and design itself.

Supported on evolutive design, the local sources and culture are not ignored, although the focus is fundamentally placed on an internationalist approach based on universal memory. The approach is focused on concepts of memory, culture and evolutive design, in a similar way as argued by the English designer Jasper Morrison in support of Super Normal [10] exhibition and book, seeking to encourage the defence of the evolutionary step instead of the creative leap, advocating the incremental improvement of objects and life, instead of the purely formal change, as the reason for creating new products. Sam Hecht calls appropriation [12] to this idea of evolving from knowledge, from what exists, releasing any sense of plagiarism. Hara [13] refers to inspiration in products that are familiar to us, with which we live, often for generations, dealing with shared values to build stable and mature products. Enzo Mari refers to the role of the designer as a guardian of the collective knowledge [10].

\subsection{UBI Process}

The memory inevitably refers to local culture. When designing something based on evolutive principles, based on what is known, the resemblance of comfort provided by familiarity [10], by the memory imbedded in the objects of the houses of our ancestors, the recognition and emotional value, becomes more important than purely formal options [14]. It is necessary to protect this local memory which, according to Sam Hecht [15], is almost reduced to very cheap products. But this memory and reference to existing products, some insistence on local inspiration, often forced as a marketing tool, seem to have occupied a good part of the universe, speech and design.

The evolution of design is today made by the mixture, the openness, the advance of universal and tolerance values, a richness that is also central on the approach of UBI design courses. More than looking for roots exclusively on local culture, the work is developed based on both local and international references, ancient and current references, always with care not to decontextualize them [16]. It refers to the knowledge shared by all, to the archetypes we carry inherited by collective unconscious [17] and to the familiarity or personal experience that is different for each one of us [18]. It is believed that this argument is as valid in a small university as in a large one, in a peripheral or central city. If a school is, in part, defined by the place where it is located, it is even more built by the people who are part of it. In the industrial design course at UBI only $4 \%$ of professors are local, and only $12 \%$ live in the region. Also, only $12 \%$ were graduated in peripheral schools. The coexistence of the two universes, peripheral and central, slow and fast paced, smooth and tense [19] provides an observation of two worlds, and this blend also becomes a value. There's work based on local references, personal references, but also remissive to other sites and cultures, international, universal and unplaced references, and it is this diversity of backgrounds that provides the results.

\subsection{Local and national culture vs international influence}

Yet, local culture is not ignored. While most projects are developed with industry across the country, particularly the more industrialised North, local industry is also a usual partner on the exercises. This is the case of the projects developed for Burel Factory, a textile company from the region, that manufactures woollen fabrics and has developed a successful brand for the global market.

The national culture is also visited. In the project The Hard Life [20], whose brief suggests the development of redesigns for the objects registered in the book published by the English designer Jasper Morrison with the same name, and in which he photographed and commented a selection of 
artefacts exhibited in the National Museum of Ethnology in Lisbon, the projects rethink and modernise artefacts with origin in diverse regions of the country. Projected for eventual production by Bisarro, a company that produces contemporary designs using traditional black ceramic techniques from Bisalhães, Trás-os-Montes, in the northeast of the country, and which belongs to two former students graduated in industrial design at this school, the national character of the projects becomes obvious by the origin of the redesigned artefacts and partnership.

The fact that the project was based on Morrison's choices and interpretation acquires central importance. In the original selection, the author chose local artefacts, yet not of his own local culture, opening the way to the kind of enrichment and cultural mixtures that the course and design discipline seek to explore and which, in our view, characterise and are fundamental qualities of contemporary design. Morrison's choice is certainly tainted by his own experience with his local English culture, and so may be the student's work. Importing unconsciously their own experiences with the chosen objects, but also mixing influences of similar artefacts from around the world, meanwhile discovered in the research process phase, they transform the national base into truly contemporary design, respecting heritage, but also adapting those designs to contemporary life and freeing them from the nostalgia that could lock them up. There is, in the process of open investigation encouraged by the internationalist approach of the course, the intentional creation of conditions for the accommodation of external influences. These influences are sometimes direct, referring to specific products, sometimes made by importing the conceptual approach of the design of other regions, like Nordic and Japanese, so often and consistently characterised by the balance between the influences of the past and the needs of the present [21]. But external influences are not limited to products with strong local roots, are often also influenced by wider movements such as Modernism or more contemporary products and approaches. If inspiration is sometimes national or local, reinterpretation is open to all influences, local, of other locals or universal. At a critical context of detachment, protectionism and nationalism, this crossroads seeks to emphasise the prospective role of design as an area of integration and intersection. More than in the shapes, than in the apparent silhouettes, the influence is present in the visit made to concepts proposed by contemporary designers and thinkers.

\subsection{UBI Steps - Sequential and Slow}

The process used seeks to be coherent with the suggested approach, as well as to lay the foundations for the weighted development of a rich and complete decision process. Knowledge of design history is inescapable in any design studies structure, becoming even more important if we consider the evolutive design approach suggested. To achieve the referred subtle improvement, the analysis of behaviour, use and gesture, as well as of the social context, becomes also of major importance. Sketch and draw are other fundamental tools to support reflection and thought, the main resources. Specific training in each of these areas is a great part in the initial structure of both cycles.

The project method promotes the observation and information gathering, the decision making by the designer, and seeks to be deeply supported in culture to the detriment of the use of statistical processes. The method for the development of the projects, based on a sequential process and interdependence of the diverse steps, promotes a slowdown which intends to promote thought, by opposition to the acceleration which, according to Jonathan Ive [22], occupied the design process and drastically reduced the time for reflection. The memory-based approach and internationalist vision is present throughout the process, with special focus on the initial phase, the research, in the analysis of use, habits, gestures and behaviours, in the visit to the history of design, at least in the specific area of work, and in the search for similar items and similar uses. The second phase of the process, the suggestion of a concept, refers to actions and typologies that allow solving the challenges, often based on the memory of existing routines. The third phase, the sketch, initiates the materialisation of product suggestions, often based on familiar forms, emphasising the evolutive design approach. Next, the drawing, allows the designer to reflect about all the details still in a pre-technical phase. The execution of manual models, usually developed in real scale, allows realising a first concretisation of the product volume. The sixth phase, model making, completes the product conception tasks, only leaving three final tasks to the end: packaging, branding and communication.

Throughout all the process, freedom and autonomy in decision-making and management of tasks, as well as in the strict ordering, is encouraged. Although, it is never encouraged to go around the need for reflection, in an approach that opposes any strategy that may tend to reduce the understanding of design to a merely technical job, or to a task. 
Some of the strategical decisions made regarding the approach, the process, the relation with local and universal cultural memory, can be observed in student's projects in Figure 1. Biombo and Dez projects refer to the local culture, whether in the use of the wool fibres of Biombo screen, or in the inheritance of the wood work typical in the mountain village of Dez, being both contaminated by a more contemporary and accessible approach. In Churra, the improvement of an artefact of the national culture is done by eliminating the legs, reducing the form to its essential, its basic geometry. Bisalhas, also based on national memory, is highly influenced by the view of Hecht and Colin [12], reflecting its need to belong to the landscape, to coexist with the world where it will be placed and the objects with which it will interact, clearly referring to Hecht and Colin's Formwork set in concept and communication. In the set of pots and pans As Marias, the culture of national cookware is sought in the materials, and the shape in contemporary design, the same approach observed in Soho, whose silhouette refers to the archetype, but also to simplicity and contemporary vision of Konstantin Grcic's Coup, and to the liquidity and softness of Bouroullec's Ovale. Also displayed sketches and models.

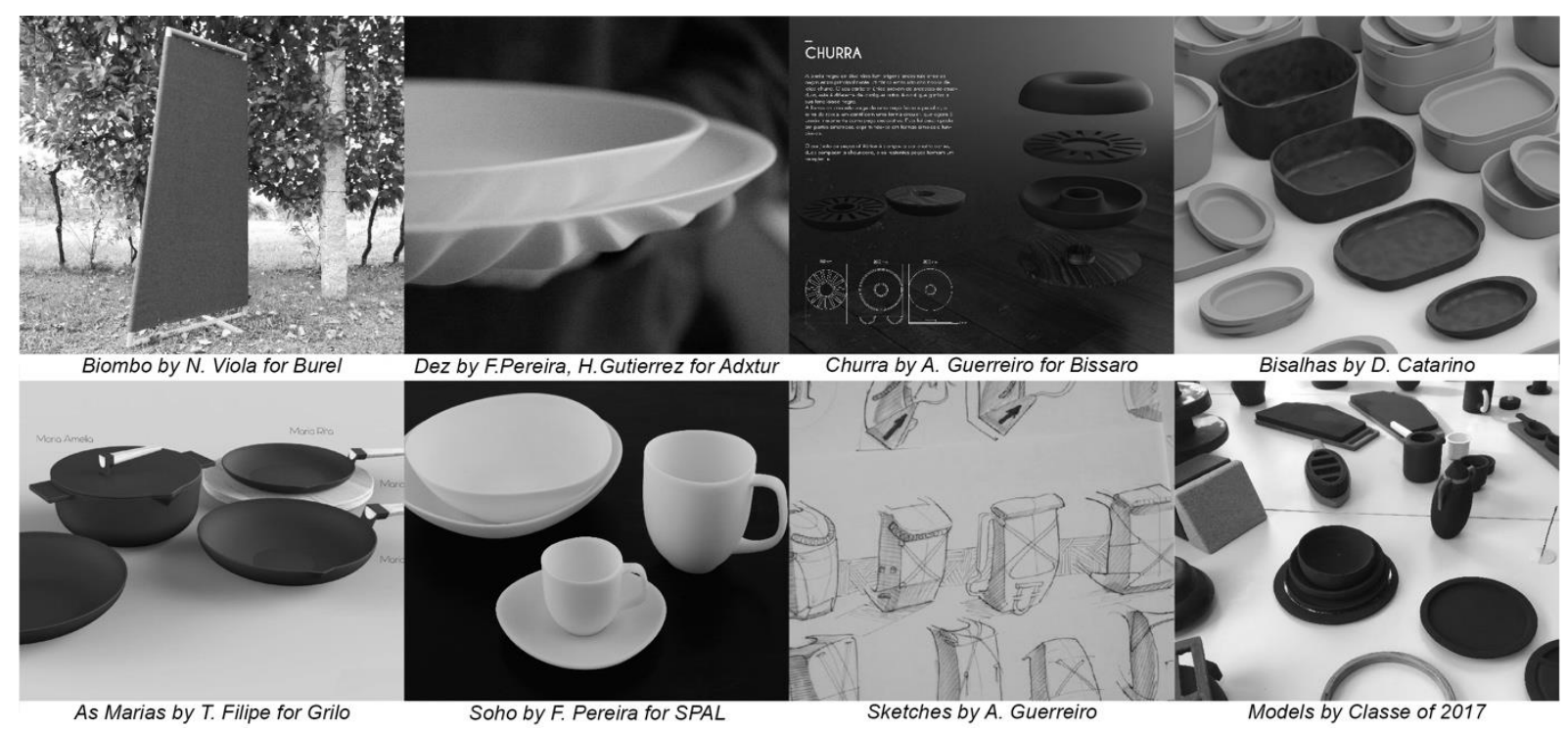

Figure 1. Examples of projects developed by students under the authors supervision

\section{DISCUSSION \& CONCLUSION}

Considering the material resources available today, the easy access to information and digital production means, there are no quality limitations implicit to the operation of a design course in a peripheral region. Even so, there is still a greater difficulty in attracting talents and students, which can only be contradicted by the existence and communication of a clear and consistent approach to training needs of future designers, as well as the needs of the real world. This notion must be supported by scientific and pedagogical quality of the course and embraced by a strategic view consistent with the local culture, well integrated and related to the national and international scene. The development and implementation of these aspects by all the course team, teaching and nonteaching staff, will have to be supported by the governing bodies of the institution and should eventually be supported by a national policy to support the development of higher education in the interior.

The recognition of personal and collective memory, with local and international references; the support of inherent cultural enrichment; the clear statement of evolutive design, which knows how to learn with all kinds of objects (vernacular, modern or contemporaneous), and responds to specific needs of users and ultimately intendeds to create a higher-quality material culture, more benign to humans and the environment [24]; and the opposition to design based on the search for form by the form and the protagonism of its authors in the star system devoid of content, represent a character of honesty that can be distinctive in the context of training in industrial design.

Despite the disadvantages associated with the location in low density regions, the success of an industrial design course requires the definition of objectives and contents consistent with the strategic vision, at the macro level, but also with current pedagogical day-to-day practices, at an operational level, in a very clear approach and with an effective communication. 
The sense of proximity towards industrial production, that supported the growth of many schools, seems to have created the expectation that each course should focus on the development of projects based on the local tradition and heritage. In the case of the UBI, in each contact by the industry, in each workshop with an external guest, the reference to the local wool industry always seems to be latent. Instead, the wide and clear internationalist influence on four prized projects in an international lighting design competition, although praised, was referred as surprising. The expectation seems to be that the products are developed for the region, also not considering that a large percentage of students, about $80 \%$, are not native to the region.

It is possible, with the modesty of a small inner university, to develop a successful course for the region and the country, if it is based on a clear and consistently implemented strategy linked to local memory, but open to the world. Local memory is fundamental, it must be preserved, but never confused with the need for diversity. There is at least the need to avoid any confusion with some nostalgic burden that can be understood as a role of design in the reconstruction of the past, or in the recovery of nationalist or regional identity. The success of the course can work as an element of promotion of the region, even if, on the long run, that won't necessarily mean a significant fixation of young communities in these regions.

\section{ACKNOWLEDGMENTS}

This article is a result of the project Design Obs. Para um Observatório de Design em Portugal: Modelos, Instrumentos, Representação e Estratégias, supported by Lisbon Regional Operational Programme (LISBOA 2020) and the Competitiveness and Internationalisation Operational Programme (POCI-01-0145-FEDER-032445), under the PORTUGAL 2020 Partnership Agreement, through the European Regional Development Fund (ERDF) and FCT - Fundação para a Ciência e a Tecnologia.

\section{REFERENCES}

[1] Banco de Portugal. As indústrias transformadoras em Portugal 2012-2016. BdP. 2018.

[2] INE. Estatísticas do Comércio Internacional - Dezembro 2018. INE. 2018.

[3] Movimento pelo Interior. Relatório Final e Informação complementar. 2018. Available: http://www.movimentopelointerior.org [Accessed on 2019, 5 March].

[4] DGES. Dados e Estatísticas de Cursos Superiores - Base de Dados de Junho 2018. Available: http://www.infocursos.mec.pt [Accessed on 2019, 5 March].

[5] Designboom. Dieter Rams Interview. 2000 http://www.designboom.com/interviews/dieter-ramsdesignboom-interview [Accessed on 2019, 5 March].

[6] The Economist. The third industrial revolution. The Economist Apr $21^{\text {st }}$, 2012. Available: http://www.economist.com/node/21553017 [Accessed on 2019, 5 March].

[7] Bohm F. KGID Konstantin Grcic Industrial Design. 2005. (Phaidon Press, London)

[8] Interview with Konstantin Grcic. In V. Cuiffi (Ed.), (pp. 1-12). Milano: Klat Mag. 2010.

[9] Grcic K. Utopia in the Everyday K. Grcic - Panorama. Weil am Rhein: Vitra Design Museum.

[10] Fukasawa N. and Morrison J. Super normal. 2007. (Lars Muller Publishers, Baden)

[11] Kries M. (ed) Konstantin Grcic: Panorama. 2014. (Vitra Design Museum, Weil am Rhein)

[12] Hecht S. and Colin K. Product as Landscape. 2005. (Industrial Facility, London).

[13] Hara K. Designing design. 2007. (Lars Muller Publishers, Baden).

[14] Schmidt P. Who is Afraid of Red, Yellow and Blue? Grid. February 2003.

[15] Colin K. and Hecht S. Usefulness in Small Things. 2010. (Rizzoli International, New York).

[16] Bey J., Bouroullec R. and Bouroullec E. SOS Design. Milano: Abitare. 2010, July.

[17] Jung C.G. Synchronicity: an acausal connecting principle. 1972. (Routledge, Oxford).

[18] Terstiege G. Die Lebensbegleiter. Form. July 2009.

[19] Scholze J. and Ross J.. No Cosy Corners. Disegno. October 2013.

[20] Borges A. and Vicente J. The Hard Life: A Pedagogical Experience in Industrial Design. In: Rebelo F. and Soares M. (eds) Advances in Ergonomics in Design. AHFE 2018. Advances in Intelligent Systems and Computing, vol 777. pp. 561-571. 2019 (Springer, Cham).

[21] Borges A. Normal, memória, invisibilidade e significado nos objectos. PhD Thesis. UA. 2015.

[22] Hustwit G., et al. Objectified. London: Swiss Dots Limited. 2009.

[23] Alves D., Pacheco L.P., Vicente J. and Sousa G. Vernacular Living as a Model for Innovation and Sustainability: The Wood Furniture of Minho Region. In Correia, M. (ed); Vernacular Heritage and Earthen Architecture; pp.843-848. 2013. (CRC Press, Boca Raton). 